Arq. Bras. Med. Vet. Zootec., v.56, n.6, p.709-714, 2004

\title{
Diagnóstico da pneumonia enzoótica suína pela técnica da imunoperoxidase
}

\author{
[Immunoperoxidase technique for diagnosis of enzootic pnemonia in swine] \\ F.C. Ribeiro, J.C.P. Silva, J.L. Santos, K.C.S. Pontes \\ Departamento de Veterinária da Universidade Federal de Viçosa \\ Av. PH Rolfs, s/n \\ 36571-000 - Viçosa, MG
}

\begin{abstract}
RESUMO
Avaliou-se a técnica da imunoperoxidase como método auxiliar para a deteç̧ão de Mycoplasma hyopneumoniae em suínos naturalmente infectados. Foram colhidos 80 fragmentos de pulmões de 40 animais provenientes de granjas consideradas negativas e 40 de granjas com diagnóstico positivo de pneumonia enzoótica. Com a utilização de soro policlonal específico (IgG de coelho anti- $M$. hyopneumoniae) observou-se correlação positiva de $77 \%$ entre os diagnósticos microscópicos e imunoistoquímicos, enquanto que a correlação entre os diagnósticos macroscópico e imunoistoquímico foi de $49 \%$. Nas granjas consideradas negativas observou-se presença de discreta imunorreação em 22,5\% dos casos, o que poderia indicar a existência de reação cruzada com outros microrganismos. Nas granjas com diagnóstico positivo para pneumonia enzoótica a técnica da peroxidase-anti-peroxidase (PAP) revelou diferentes graus de intensidade, variando de fraca imunomarcação até espesso depósito amarronzado no epitélio ou na luz das vias aéreas, ou ainda no interior de macrófagos, com relação direta entre a intensidade das lesões e da imunorreação. A técnica imunoistoquímica possui sensibilidade de $95 \%$ e especificidade de $77,5 \%$, podendo ser recomendada como ferramenta auxiliar, rápida e de baixo custo para o diagnóstico de pneumonia enzoótica suína em laboratórios de rotina em histopatologia.
\end{abstract}

Palavras-chave: suíno, imunoistoquímica, pneumonia enzoótica, Mycoplasma hyopneumomiae

\begin{abstract}
The immunoperoxidase technique as an auxiliary method for the detection of Mycoplasma hyopneumoniae in naturally infected pigs was evaluated. Eighty lung fragments of which 40 from animals of farms considered negatives and 40 of farms with positive diagnosis of enzootic pneumonia were collected. The results obtained with polyclonal specific serum (IgG of rabbit anti - M. hyopneumoniae) evidentiated a positive correlation of $77 \%$ between microscopic and immunohistochemical diagnoses, while the correlation between the macroscopic and immunohistochemical diagnoses was of $49 \%$. In the farms considered negatives the presence of discrete immunoreaction in $22.5 \%$ of the cases, what could indicate the existence of cross reaction with other microorganisms, was observed. In the farms with positive diagnosis for enzootic pneumonia the peroxidase-anti peroxidase technique revealed different degrees of intensity, varying from weak immunomarcation to thick brownish deposit in the epithelium or in the light of the airways, or still inside macrophages, with a direct relationship among the intensity of the lesions and the immunoreaction. It was also verified that the immunohistochemistry technique presented $95 \%$ of sensibility and $77.5 \%$ of specificity, being recommended as auxiliary, fast and of low cost tool for the diagnosis of swine enzootic pneumonia in routine laboratories of histopathology.
\end{abstract}

Keywords: swine, immunohistochemistry, enzootic pneumonia, Mycoplasma hyopneumoniae

Recebido para publicação em 16 de dezembro de 2002

Recebido para publicação, após modificações, em 16 de julho de 2003

E-mail: jcpsilva@ufv.br 


\section{INTRODUÇÃO}

A pneumonia enzoótica suína é uma doença altamente contagiosa, de distribuição cosmopolita, caracterizada por alta morbidade, baixa mortalidade, tosse crônica e retardo do crescimento (Oboegbulen, 1981). Tem como agente etiológico o Mycoplasma hyopneumoniae encontrado na mucosa respiratória, aderido ao epitélio ciliado da traquéia, brônquios e bronquíolos (Stevenson, 1998). A transmissão do agente pode ocorrer pelo contato direto das secreções respiratórias do suíno portador ou por aerossóis, a partir de animais infectados em um rebanho livre (Stevenson, 1998).

Segundo Kahane e Razin (1969), os principais determinantes antigênicos dos micoplasmas estão localizados na membrana. Messier e Ross (1991) evidenciaram que esses microrganismos possuem fatores mitogênicos para linfócitos, os quais seriam responsáveis pelas hiperplasia linfóide peribronquiolar característica da doença. Os micoplasmas são considerados super-antígenos (Mims et al., 1995), capazes de estimular excessivo número de células T pela exposição de vários epitopos simultaneamente. Escapa das defesas naturais do hospedeiro fixando-se firmemente à sua mucosa respiratória (Yamamoto, 1994), podendo sua localização no lúmen explicar a dificuldade de eliminação do agente. Além disso, o micoplasma tem a habilidade de mimetizar várias superfícies antigênicas e utilizar-se dessa variação para evadir-se do sistema imune (Done, 1996).

O micoplasma se dissemina rapidamente sob condições ambientais favoráveis em suínos na fase de crescimento e terminação. Práticas inadequadas de manejo, incluindo alta densidade, falta de higiene das instalações e fatores ambientais associados, como ventilação inadequada, podem aumentar a concentração de contaminantes aéreos, o que potencializa os impactos da pneumonia suína. A doença está disseminada nas criações brasileiras (Moreno et al., 1999).

Diante da natureza, da especificidade e da complexidade de fatores envolvidos com essa patologia, o diagnóstico rápido e preciso da pneumonia enzoótica, e sobretudo do(s) agente(s) etiológico(s) envolvido(s), é imperativo (Le Potier et al., 1994). Graças às características singulares dessa enfermidade, o diagnóstico presuntivo pode ser realizado pela conjunção dos sinais clínicos e dos aspectos macroscópicos e microscópicos das lesões (Ahrens, Friis, 1991; Ross, Stemke, 1995; Done, 1996). Todavia, esse procedimento possui uma parcela de subjetividade e de imprecisão, sendo necessários exames complementares para a confirmação do diagnóstico. A fim de se evitar diagnóstico inconclusivo e controverso sobre a etiologia do processo, muitas vezes o cultivo e o isolamento do agente tornam-se necessários. No entanto, por se tratar de um microrganismo de caráter fastidioso, de crescimento lento e que requer meio seletivo, complexo e de alto custo para o seu crescimento, as técnicas para seu isolamento não são rotineiramente utilizadas (Hurnik et al., 1993). Além disso, a utilização de antibióticos e outros quimioterápicos na alimentação pode também mascarar e comprometer os resultados desse procedimento microbiológico.

As técnicas sorológicas, dentre elas o ELISA, possuem alta sensibilidade, mas devido à ocorrência de reações cruzadas com Mycoplasma flocculare, possuem limitações quanto à sua utilização (Ross, Stemke, 1995). Os métodos sorológicos detectam os títulos de anticorpos, mas não confirmam a ocorrência de infecção. A imunofluorescência foi ocasionalmente utilizada para o diagnóstico de pneumonia enzoótica por ser barata, simples e prática (Armstrong, 1994). Contudo, existem restrições ao seu uso, uma vez que requer amostras recentes do material a ser examinado e microscópio de luz ultravioleta, de custo elevado.

Os inconvenientes das técnicas citadas estimulam a busca de métodos compatíveis com os processos diagnósticos de rotina. Adicionalmente, em determinadas circunstâncias torna-se necessária a utilização de técnicas que possuam alta especificidade, capazes de detectar determinantes antigênicos envolvidos com a gênese do processo mórbido. A sensibilidade do método diagnóstico pode vir a ser importante ferramenta, capaz de monitorar o estado de higidez de um rebanho e detectar um possível início da enfermidade, antes mesmo que a doença clínica se manifeste. A imunoistoquímica (IHQ), ao combinar técnicas morfológicas, imunológicas e bioquímicas, desponta como instrumento promissor para o diagnóstico de agentes infecciosos (Gimeno, 1995). Essa 
técnica, utilizando a enzima peroxidase (PAP) como molécula marcadora, é facilmente exeqüível e de metodologia simples, e tem como vantagens a rapidez e o baixo custo, além de produzir material corado durável (Hsu et al., 1981; Morales, 1993).

O objetivo deste trabalho foi avaliar a técnica da imunoperoxidase como instrumento complementar para o diagnóstico de pneumonia enzoótica em suínos, verificando a sensibilidade e especificidade do método e sua eficiência para o monitoramento da pneumonia micoplásmica em criações de suínos.

\section{MATERIAL E MÉTODOS}

Foram utilizados 80 fragmentos de pulmões de suínos, predominantemente do tipo carne, com aproximadamente cinco meses de idade, pesando cerca de $100 \mathrm{~kg}$ e oriundos de criações intensivas da Zona da Mata de Minas Gerais. De acordo com o estado sanitário das granjas, definiu-se previamente por obter 40 fragmentos de pulmões provenientes de granjas positivas para pneumonia enzoótica suína, isto é, aquelas cujos rebanhos apresentaram manifestações clínicas e morfológicas da doença, e 40 fragmentos de pulmões de granjas consideradas livres de $M$. hyopneumoniae, ou seja, aquelas sem histórico clínico da doença desde a sua implantação.

Após o abate, os pulmões foram identificados e examinados, e os aspectos morfológicos anotados em protocolo próprio. Baseado no aspecto macroscópico os pulmões foram divididos em escores, a saber: (1) sem lesão aparente, (2) com processos congestivohemorrágicos nas regiões antero-ventrais e (3) com lesões típicas de pneumonia enzoótica, caracterizadas por áreas de consolidação, de coloração vermelho púrpura nas regiões anteroventrais. As amostras de tecido pulmonar foram colhidas, fixadas em formol neutro a $10 \%$, processadas segundo técnicas rotineiras em histopatologia, e coradas pela HE. De acordo com seu aspecto microscópico, os fragmentos foram agrupados em: (1) normal, (2) com infiltração linfocítica peribronquiolar com início de hiperplasia linfóide e (3) com exsudação celular e hiperplasia linfóide exuberante. Cortes foram obtidos para realização da imunocoloração pela técnica da peroxidase-anti-peroxidase
(PAP), utilizando os procedimentos preconizados por Sternberger (1986). Com base na intensidade da imunocoloração, os fragmentos foram distribuídos em: (1) imunomarcação ausente, (2) discreta imunorreação no epitélio respiratório e (3) evidente imunomarcação no epitélio bronquial e bronquiolar e no interior de macrófagos.

A sensibilidade e a especificidade desse método imunoistoquímico foram calculadas a partir da distribuição de freqüências (Fletcher,1986) tomando como padrão o histórico, os sinais clínicos, os aspectos morfológicos dos pulmões e a confirmação sorológica. Fez-se análise estatística descritiva e estimou-se o coeficiente de correlação de Pearson (r) entre as variáveis macroscopia, microscopia e imunocoloração pelo PAP.

\section{RESULTADOS E DISCUSSÃO}

Dos 40 fragmentos de pulmões provenientes de granjas consideradas livres de $M$. hyopneumoniae, 34 (85\%) não apresentaram lesão aparente ao exame macroscópico e seis $(15 \%)$ exibiram apenas discretas alterações circulatórias, caracterizadas por discreta hiperemia focal. Nos 40 fragmentos de pulmões colhidos de granjas positivas para pneumonia enzoótica, $16(40 \%)$ não revelaram lesões aparentes ao exame macroscópico, cinco (12,5\%) exibiram alterações circulatórias, caracterizadas pela presença de áreas avermelhadas nas regiões antero-ventrais dos pulmões, e 19 (47,5\%) apresentaram lesões características de pneumonia, traduzidas por áreas hipocreptantes, hepatizadas e de coloração que variou do púrpura ao cinza, localizadas eletivamente nas porções ventrais dos lobos apicais. Essas áreas eram bem definidas, com clara delimitação com o parênquima pulmonar circunjacente que por vezes se exibia ligeiramente enfisematoso. À abertura das vias aéreas verificou-se presença de exsudato catarral a purulento no interior dos brônquios como descrito por Maes et al. (1996).

O exame histológico dos pulmões provenientes das granjas consideradas negativas revelou que $39(97,5 \%)$ fragmentos apresentaram-se dentro do limite de normalidade e que apenas um $(2,5 \%)$ exibiu discreta hiperplasia linfóide no tecido pulmonar. As amostras provenientes de 
granjas positivas revelaram presença de lesões inflamatórias em todos os pulmões. Em 20 (50\%) fragmentos verificou-se aumento do número de linfócitos nas áreas perivasculares e peribronquiais, com formação de pequenos aglomerados linfóides. Com base nas observações de Done (1996), Maes et al. (1996) e Ross (1999), essas lesões podem ser consideradas micoplásmicas. Nos outros 20 $(50 \%)$ fragmentos observou-se evidente hiperplasia linfóide nas áreas adjacentes aos ductos aéreos associada à exsudação celular relativamente intensa, com predomínio ora de neutrófilos, ora de linfócitos, indicando resposta inflamatória mais intensa. Segundo Livingston et al. (1972); Done (1996); Maes et al. (1996) e Ross (1999), isso pode levar ao aparecimento de áreas atelectásicas e áreas de enfisema compensatório que se desenvolvem secundariamente às áreas de restrição do parênquima adjacente.

A imunoistoquímica de pulmões de animais provenientes de granjas negativas revelou nove $(22,5 \%)$ amostras com discreta imunorreação e $31(77,5 \%)$ sem evidências de reação imunoistoquímica (Fig. 1). O exame imunoistoquímico dos pulmões oriundos de granjas positivas revelou duas (5\%) amostras sem imunomarcação, 17 (42,5\%) com reação tênue, caracterizada pela presença de delgada camada de aspecto bronzeado na superfície epitelial de brônquios e bronquíolos, e 21 (52,5 \%) com evidente imunomarcação, traduzida por espesso precipitado de coloração amarronzada na superfície do epitélio de revestimento ou na luz das vias aéreas, sobretudo nos brônquios e bronquíolos (Fig. 2), também visualizada no interior de macrófagos. O número e o percentual de suínos distribuídos com base nos aspectos macroscópicos, microscópicos

imunoistoquímicos são apresentados Tab. 1. O padrão de coloração imunoistoquímico observado guarda estreita similaridade com os obtidos por Bruggman e Enberg (1977); Lutsky et al. (1986) e Doster e Lin (1988). Segundo Bruggman e Enberg (1977), o agente se faz presente sob a forma de colônias ou ainda distribuído ao acaso na superfície de células epiteliais, o que dá um aspecto irregular ao precipitado. Lutsky et al. (1986) observaram que o depósito bronzeado na superfície epitelial era extracelular, limitado aos cílios. Observaram ainda que esse depósito não era contínuo e que também poderia estar presente no interior de algumas glândulas da submucosa, fato também observado no presente trabalho. Verificou-se, ainda, imunomarcação com diferentes graus de intensidade, mais evidente nas áreas de maior lesão, de forma similar ao relatado por Rodriguez et al. (1996). Bashiruddin et al. (1999) consideraram os locais de imunomarcação mais intensa como áreas de maior concentração do antígeno, correspondendo aos locais de lesões mais desenvolvidas. Para Doster e Lin (1988), animais cronicamente afetados podem exibir pequena concentração de microrganismos, o que poderia justificar a imunomarcação mais tênue verificada neste trabalho, em alguns pulmões oriundos de granjas positivas.

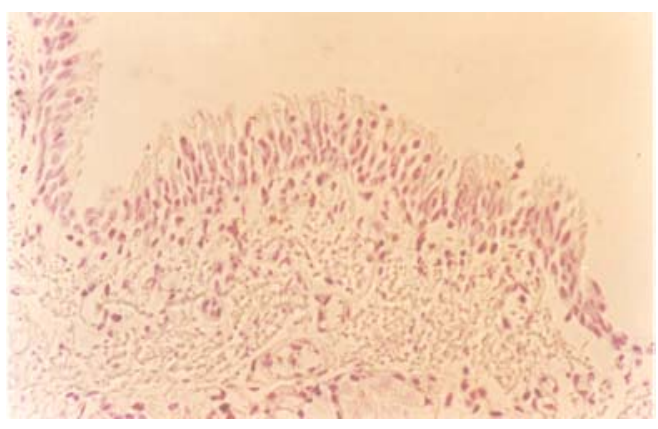

Figura 1. Pulmão de suíno - Ausência de imunomarcação no epitélio respiratório. PAP. $400 \times$.

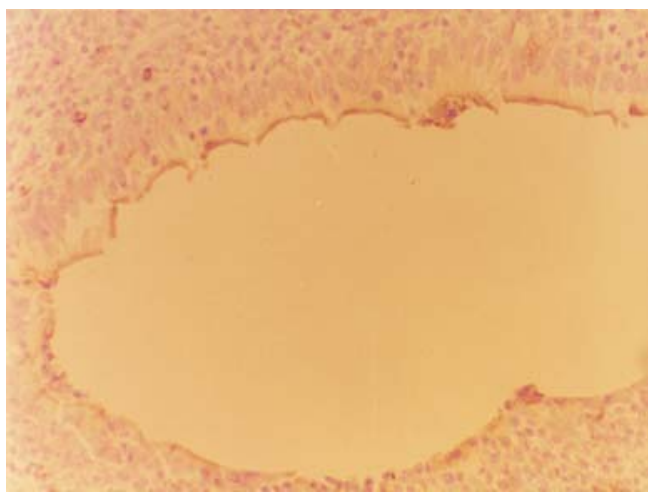

Figura 2. Pulmão de suíno - Superfície epitelial exibindo imunorreação. PAP. 400×. 
Tabela 1. Frequência relativa de diagnósticos morfopatológicos em pulmões de suínos oriundos de granjas positivas e negativas para pneumonia enzoótica

\begin{tabular}{|c|c|c|c|c|c|c|}
\hline \multirow[t]{3}{*}{ Método } & \multicolumn{3}{|c|}{ Granja positiva } & \multicolumn{3}{|c|}{ Granja negativa } \\
\hline & \multicolumn{3}{|c|}{ Escore } & \multicolumn{3}{|c|}{ Escore } \\
\hline & 1 & 2 & 3 & 1 & 2 & 3 \\
\hline Macroscopia & $16(40,0 \%)$ & $05(12,5 \%)$ & $19(47,5 \%)$ & $34(85,0 \%)$ & $06(15,0 \%)$ & $0(0,0 \%)$ \\
\hline Microscopia & $0(0,0 \%)$ & $20(50,0 \%)$ & $20(50,0 \%)$ & $39(97,5 \%)$ & $01(02,5 \%)$ & $0(0,0 \%)$ \\
\hline Imunoistoquímica & $02(5,0 \%)$ & $17(42,5 \%)$ & $21(52,5 \%)$ & $31(77,5 \%)$ & $09(22.5 \%)$ & $0(0,0 \%)$ \\
\hline
\end{tabular}

Observou-se correlação positiva $(\mathrm{r}=0,69)$ entre os diagnósticos macroscópico e microscópico, indicando correspondência entre essas manifestações e demonstrando o valor preditivo dessas alterações para fins de diagnóstico da pneumonia enzoótica. A intensidade das reações pelas técnicas histológicas e imunoistoquímicas também apresentaram correlação positiva $(\mathrm{r}=0,77)$, indicando que a presença de lesão está associada à presença de $M$. hyopneumoniae (Tab. 2). A estimativa de correlação entre os métodos macroscópico e imunoistoquímico foi menor $(\mathrm{r}=0,49)$. A ausência de lesões macroscópicas em pulmões oriundos de granjas positivas, cujos fragmentos correspondentes deram reação positiva ao PAP, a princípio poderia indicar incipiente colonização pelo $M$. hyopneumoniae ainda sem manifestação morfológica da doença, ou existência de reações cruzadas com outros agentes biológicos, sobretudo com o $M$. flocculare.

Tabela 2. Coeficientes de correlação e significância $(\mathrm{P})$ entre as intensidades das lesões macroscópica (macro), microscópica (micro) e imunomarcação pelo PAP

\begin{tabular}{lcc}
\hline Método & Correlação & $\mathrm{P}$ \\
\hline Micro/ PAP & 0,77 & 0,0001 \\
Macro/ Micro & 0,69 & 0,0001 \\
Macro/ PAP & 0,49 & 0,0001 \\
\hline
\end{tabular}

De acordo com a presença ou ausência da imunorreação nas granjas positivas e negativas, calcularam-se a sensibilidade e a especificidade da técnica de peroxidase anti-peroxidase, de acordo com o que foi preconizado por Fletcher (1986). Os resultados indicaram tratar-se de uma técnica de alta sensibilidade (95\%) e de moderada especificidade $(77,5 \%)$. Por se um anticorpo policlonal e diante da possibilidade de ocorrência de reações cruzadas com o $M$. flocculare, a especificidade dessa técnica é questionável. Alguns autores têm enfatizado os efeitos indesejáveis dessa reação quando se busca o diagnóstico etiológico da enfermidade (Kwon, Chae, 1999). Neste trabalho, essa indesejável reação cruzada poderia estar presente e explicar a visualização da discreta imunorreação em nove (22,5\%) animais provenientes de granjas consideradas negativas para $M$. hyopneumoniae.

Apesar da moderada especificidade, a técnica da peroxidase anti-peroxidase revelou grande sensibilidade, podendo ser utilizada rotineiramente em laboratórios de histopatologia como ferramenta auxiliar no diagnóstico de pneumonia enzoótica suína.

\section{REFERÊNCIAS BIBLIOGRÁFICAS}

AHRENS, P.E.; FRIIS, N.F. Identification of Mycoplasma hyopneumoniae with a DNA probe. Lett. Appl. Microbiol., v.12, p.249-253, 1991.

ARMSTRONG, C.H. Porcine Mycoplasmas. In: WHITFORD, H.W.; ROSENBUSH, R.F.; LAUERMAN, L.H. (Eds.). Mycoplasmosis in animals: laboratory diagnosis. Ames: Iowa State University, 1994.

BASHIRUDDIN, J.B.; SANTINI, F.G.; DE SANTIS, P. et al. Detection of Mycoplasma mycoides subspecies mycoides in tissue from an outbreak of contagious bovine pleuropneumonia by culture, immunohistochemistry and polimerase chain reaction. Vet. Rec., v.145, p.271-274, 1999.

BRUGGMANN, S.; ENBERG, B. Demonstration of $M$. suipneumoniae in pig lungs by the enzymelinked immunoperoxidase technique. Vet. Rec., v.101, p.137, 1977.

DONE, S.H. Enzootic pneumonia (Mycoplasmosis) revisited. Pig J., v.38, p.40-61, 1996. 
DOSTER, A.R.; LIN, B.C. Identification of Mycoplasma hyopneumoniae in formalin-fixed porcine lung, using an indirect immunoperoxidase method. Am. J. Vet. Res., v.49, p.1719-21, 1988.

FLETCHER, R.H. Epidemiologia clínica: elementos essenciais. 3.ed. Porto Alegre: Artes Médicas, 1986. p.52-83.

GIMENO, E.J. Fundamentos de imunohistoquímica aplicada a patología veterinária. In: ENCONTRO NACIONAL DE PATOLOGIA VETERINÁRIA, 7., 1995, Belo Horizonte. Anais..., Belo Horizonte, 1995. P.17-51

HSU, S.M.; RAINE, E.; FANGER, H. Use of avidin-biotin-peroxidase complex (ABC) in immunoperoxidase techniques: a comparison between $\mathrm{ABC}$ and unlabeled antibody (PAP) procedures. J. Histochem. Cytochem., v.29, p.577$580,1981$.

HURNIK, D.; HANNA, P.E.; DOHOO, I.R. Evaluation of rapid gross visual appraisal of swine lungs at slaugter as a diagnostic screen for enzootic pneumonia. Can. J. Vet. Res., v.57, p.37-41, 1993.

KAHANE, I.; RAZIN, S. Immunological analysis of micoplasma membranes. J. Bacteriol., v.100, p.187-194, 1969.

KWON, D.; CHAE, C. Detection and localization of mycoplasma hyopneumoniae DNA in lungs from naturally infected pigs by in situ hibridization using a dioxigenin-labeled probe. Vet. Pathol., v.36, p.308-313, 1999.

LE POTIER, M.F.; ABIVEN, P.; KOBISCH, M. A blocking ELISA using a monoclonal antibody for the serological detection of Mycoplasma hyopneumoniae. Res. Vet. Sci., v.56, p.338-345, 1994.

LIVINGSTON, C.W.; STAIR, E.L.; UNDERDAHL, N.R. et al. Pathogenesis of Micoplasmal pneumonia in swine. Am J. Vet. Res., v.33, p.2249-2258, 1972

LUTSKY, I.; LYVNI, N.; MOR, N. Retrospective confirmation of mycoplasma infection by the immunoperoxidase technique. Pathology, v.18, p.390-392, 1986.

MAES, D.; VERDONCK, M.; DELUYKER K.A. Enzootic pneumonia in pigs. Vet. Q., v.18, p.104109, 1996.
MESSIER, S.; ROSS, R.F. Interations of Mycoplasma hyopneumoniae membranas with porcine lymphocytes. Am. J. Vet. Res., v.52, p.1497-1502, 1991.

MIMS, C.A.; PLAYFAR, J.H.; ROIT, I.M. et al. Estratégias para a sobrevivência dos parasitas e persistência da infecção. In: JAWETZ, E. Microbiologia médica. São Paulo: Manole, 1995. P.15.1-15.12.

MORALES, J.C. Técnicas de diagnostico in virología. Madrid: Diaz de Santos, 1993. 345p.

MORENO, A.M.; BARBARINI JUNIOR, O.; BACCARO, M.R. Levantamento sorológico para Mycoplasma hyopneumoniae em criações de suínos no período de dezembro de 1996 a julho de 1999.

In: CONGRESSO BRASILEIRO DE VETERINÁRIOS ESPECIALISTAS EM SUÍNOS, 9., 1999, Belo Horizonte. Anais... Belo Horizonte, 1999. P.161-162 (Resumo).

OBOEGBULEN, S.I. Enzootic pneumonia of pigs: a review. Bull. Anim. Hlth. Prod. Afr., v.29, p.269274, 1981.

RODRÍGUEZ, J.L.; OROS, J.; RODRÍGUEZ, F. et al. Pathological e immunohistochemical study of caprine pleuropneumonia induced by subspecies of Mycoplasma mycoides. J. Comp. Pathol., v.114, p.373-384, 1996.

ROSS, R.F. Mycoplasmal diseases. In: STRAW, B.E.; D'ALLAIRE, S.; MENGELING, W.L. et al. Disease of swine. 8.ed. Ames: Iowa State University, 1999. P.495-509.

ROSS, R.F.; STEMKE, G.W. Mycoplasma infections of swine. In: TULLY, J.G. \& RAZIN, S. Molecular and diagnostic procedures in mycoplasmology. New York: Academic Press, 1995. v.2, p. 275-281

STERNBERGER, L.A. Immunocytochemistry. 3.ed. New York: Editora, 1986.

STEVENSON, G.W. Bacterial pneumonia in swine. In: INTERNATIONAL PIG VETERINARY SOCIETY CONGRESS, 15., 1998, Birmingham. Proceedings... Birmingham: IPVS, 1998, P.906907. (Abstract).

YAMAMOTO, R. Mollicutes. In: BIBERSTEIN, E.L.; ZEE, Y. Tratado de microbiologia veterinária. Zaragoza: Editorial Acribia. 1994. P.241-249. 